\title{
Identification and Gradation of Wheel Loader Noise Sources
}

\author{
Feng Chi ${ }^{1,2, a}$, Xun Chen ${ }^{1, ~ b}$, Jun Zhou ${ }^{1, c^{*}}$, Yong Wang ${ }^{1, d^{*}}$, Qi Zhang ${ }^{2, \text { e }}$ \\ ${ }^{1}$ School of Mechanical Engineering, Shandong University, Jinan 250061, China \\ ${ }^{2}$ Shandong Lingong Construction Machinery Co, Ltd, Linyi 276023, China \\ a feng.chi@sdlg.com.cn, b sunger2010@qq.com, ${ }^{c}$ zhoujunpl@qq.com, ${ }^{d}$ meywang@sdu.edu.cn, ${ }^{e}$ \\ qi.zhang@sdlg.com.cn
}

Keywords: wheel loader, spectral analysis method, noise identification and gradation

Abstract. The noise control issue on construction machinery has received increasing attention in recent years. Prior to work out feasible noise control strategies, it is necessary to find out the primary noises. In this paper, main frequencies of potential noise sources was analyzed and calculated. Sound pressure level data of a $5 \mathrm{t}$ wheel loader was recorded under simulated working condition, and spectral analysis method was used to identify and grade the noise sources. The result has shown that the hydraulic pump is the primary noise component of the loader, and more attention should be focused on the pump in the course of noise control strategy making.

\section{Introduction}

With the booming of infrastructure construction across the world, the construction noise, which mainly caused by running construction machineries, together with the traffic noise, society noise and industry noise, have become the top four sources of urban noises. As one of the most commonly applied construction machineries, wheel loader, has drawn the attention of many researchers in this area.

Studies on noise control of machines started earlier in developed countries. However, most of the earlier studies focused on automobiles, ships, planes and locomotives[1-3]. Although compared to automobiles, the construction machineries are designed for special operating conditions, and move far more slowly than the automobiles, successful noise control experiences and strategies in automobile industry are exemplary. In 1981, W. NAKKULA et al. pointed out that construction machineries and automobiles have similar noise mechanisms, even though the noise level of construction machineries is much higher than automobiles[4].

However, unlike automobiles, most construction machineries are designed with hydraulic system, to work as the power source of practical operations, the noise produced by hydraulic system must be considered. A.M. WILLEMSEN et al. applied order tracking method to identify noise components related to excitation from the excavator's engine and hydraulic systems, and found out that engine rotational imbalance, engine combustion, and hydraulic pressure fluctuations are the primary components of noise generated by the excavator[5].

In this paper, a set of acoustic sensors was distributed in different locations to record the noise level of a $5 t$ wheel loader under simulated working condition, and spectral analysis method was used to identify and grade the potential noise sources.

\section{Calculation of main frequencies of potential noise sources}

For the wheel loader, the potential noise sources are noise produced by engine combustion, noise produced by engine cooling fan and noise produced by hydraulic system.

a) Engine

Engine is the power source of the whole machine, the main frequency of noise produced by noise produced by engine related component is directly determined by engine rotating speed (denoted by $n)$.

Basic frequency of engine rotating can be calculated by

$$
f=\frac{n}{60} H z
$$


For a 6-cylinder 4-stroke engine, the $1^{\text {st }}$ order frequency of noise produced by engine combustion is given by

$$
f_{e}=\frac{n}{20} H z
$$

The $1^{\text {st }}$ order frequency of noise produced by engine cooling fan shaft is determined by

$$
f_{\text {fan }}=\frac{n \times i_{\text {fan }}}{60} H z
$$

Where $i_{\text {fan }}$ is the transmission ratio between the cooling fan and engine, since a belt is applied for transmission between them.

$1^{\text {st }}$ order frequency of noise produced by cooling fan blades can be calculated by

$f_{\text {blade }}=\frac{n \times i_{\text {fan }} \times z}{60} H z$

Where $z$ is the number of fan blades.

b) Hydraulic pump

The wheel loader is equipped with a 9-tooth gear pump as the main power supply unit of working hydraulic system, and $1^{\text {st }}$ order frequency of noise produced by gear pump can be calculated by

$$
f_{p}=\frac{n \times i_{p} \times z_{p}}{60} H z
$$

Where $i_{p}$ is the transmission ratio between the gear pump and engine, and $z_{p}$ is the number of gear teeth. As we know, for a single gear tooth, a complete working cycle contains two actions, namely engagement and disengagement, thereby, the $2^{\text {nd }}$ order frequency of noise produced by gear pump should be considered.

$$
f_{p_{-} 2}=\frac{n \times i_{p} \times z_{p} \times 2}{60} H z
$$

The calculation results are given by Table 1 .

Table 1 Frequency of potential noise sources under engine speed of $2200 \mathrm{r} / \mathrm{min}$

Items

Noise frequency

Basic frequency of engine rotating

$1^{\text {st }}$ order frequency of noise produced by engine combustion

$1^{\text {st }}$ order frequency of noise produced by engine cooling fan shaft $\left(i_{f a n}=0.9\right)$

$1^{\text {st }}$ order frequency of noise produced by cooling fan blades $(z=6)$

$1^{\text {st }}$ order frequency of noise produced by gear pump $\left(i_{p}=1.1, z_{p}=9\right)$

$2^{\text {nd }}$ order frequency of noise produced by gear pump

726

\section{Sound pressure level tests}

All the tests are in accordance with standard ISO6395: 2008 - "Earth-moving machinery Determination of sound power level - Dynamic test conditions", and sound pressure data were recorded under simulated working condition.

1) Arrangement of noise measuring points

As illustrated in Fig. 1, 6 measuring points was arranged in a half spherical plane, and each measuring point was planted with an acoustic sensor. 


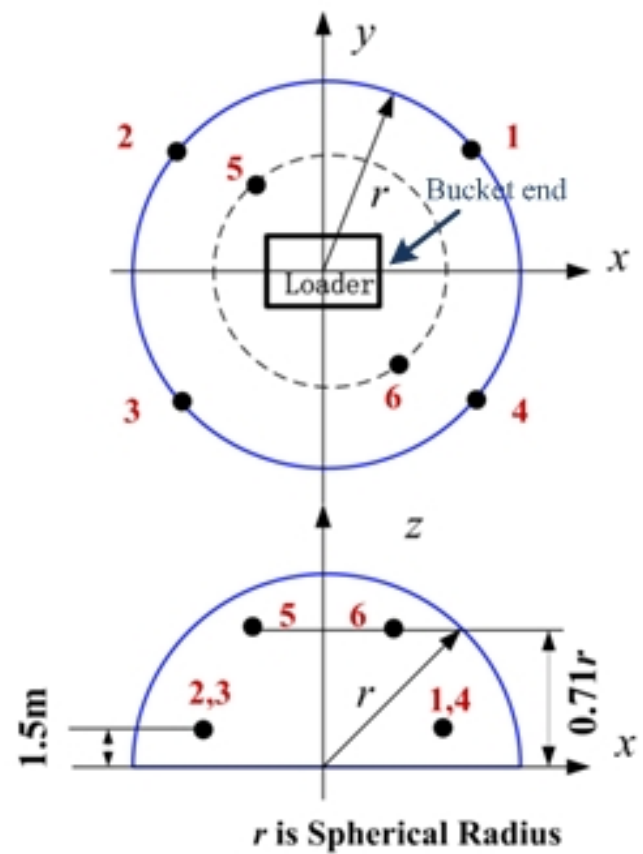

Fig. 1 Layout of acoustic sensors for sound pressure level tests (Spherical radius $r=16 \mathrm{~m}$ )

2) Test environment

The tests were carried out on concrete ground, where there is no high reflecting building within $60 \mathrm{~m}$, and the maximum ambient sound pressure level is $50 \mathrm{~dB}(\mathrm{~A})$.

3) Test conditions and measuring equipment

a) Test vehicle: Wheel loader

b) Engine speed under hydraulic operating conditions: $2200 \pm 10 \mathrm{r} / \mathrm{min}$

c) Data acquisition instrument: LMS scada02, 24-channel

d) Acoustic sensor: GRAS acoustic sensor
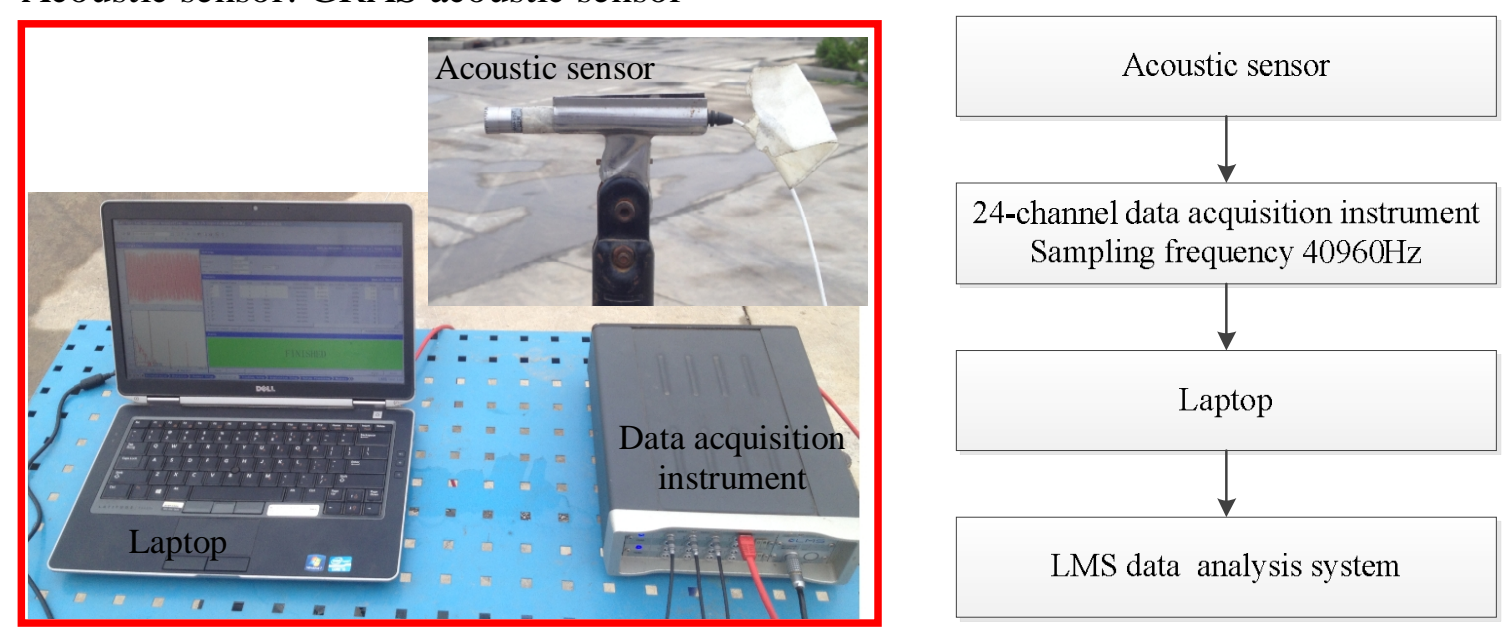

(a) Test equipment

(b) Data recording and processing flow

Fig. 2 Test principle

The test equipment and data recording and processing flow are given in Fig. 2.

\section{Noise source identification and gradation using spectral analysis method}

Spectral analysis method was used to processing the recorded sound pressure data. Spectral analysis method is a mathematical method based on Fourier transform, for a nonperiodic signal $x(t)$, its frequency spectral can be calculated by

$$
X(f)=\int_{-\infty}^{+\infty} x(t) e^{-j 2 \pi f t} d t
$$


Compared to frequency spectral, power spectrum is more commonly used to calculate sound pressure level, the calculation formulas are

$$
\begin{aligned}
& R x(\tau)=\lim _{n \rightarrow \infty} \frac{1}{T} \int_{0}^{T} x(t) x(t+\tau) d t \\
& S x(f)=\int_{-\infty}^{+\infty} R x(\tau) e^{-j 2 \pi \tau t} d \tau
\end{aligned}
$$

Where $R x(\tau)$ is the autocorrelation function of $x(t)$, and $\tau$ is the time difference.

The power spectrum of data recorded at measuring point 1 and 2 are illustrated in Fig. 3 (a) and (b) respectively. And Fig. 4 presents the sound pressure level of main frequency components at each measuring point.

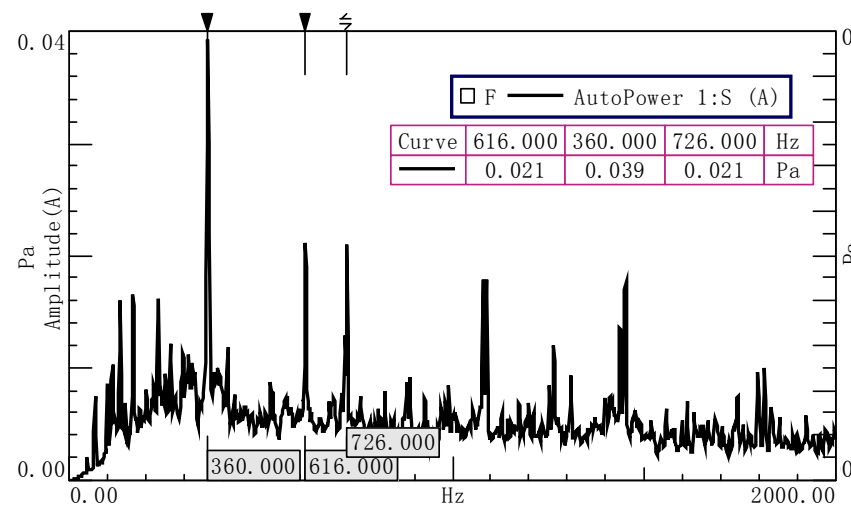

(a) Measuring point 1

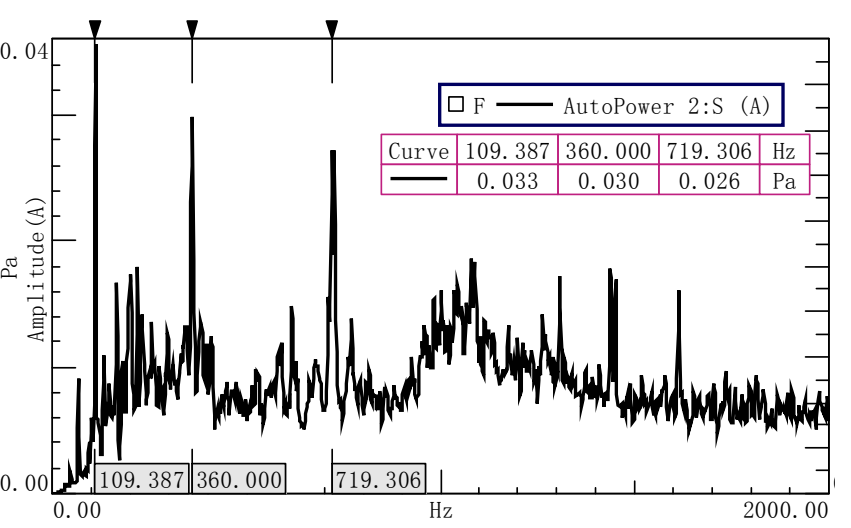

(b) Measuring point 2

Fig. 3 Power spectrum of recorded sound pressure data

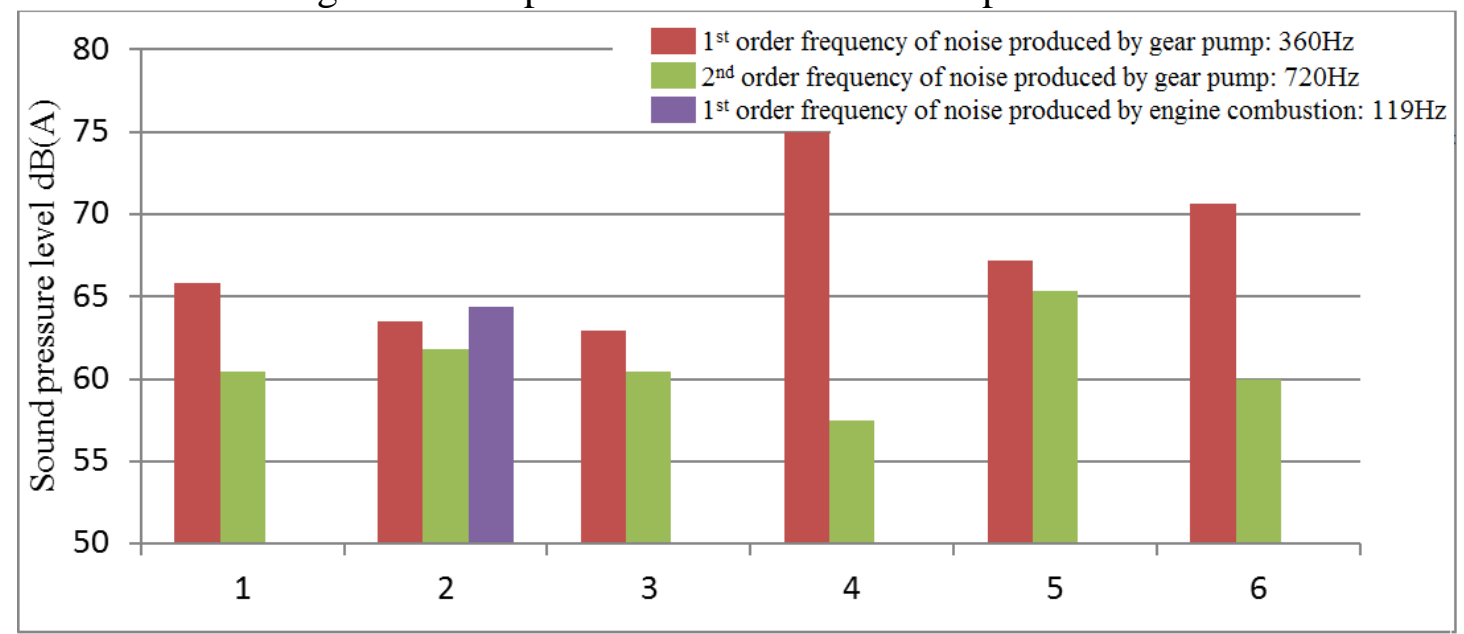

Fig. 4 Sound pressure level of main frequency components at each measuring point

It should be noted that under simulated working condition, the actual engine speed after loading is about $2181 \mathrm{r} / \mathrm{min}$, slightly smaller than the value used to calculate frequency of potential noise sources in Table 1.

Conclusions drawn from Fig. 3 and Fig. 4: The main noise frequency components are $360 \mathrm{~Hz}, 720$ $\mathrm{Hz}$ and $119 \mathrm{~Hz}$, which are the $1^{\text {st }}$ order frequency of noise produced by gear pump, $2^{\text {nd }}$ order frequency of noise produced by gear pump and $1^{\text {st }}$ order frequency of noise produced by engine combustion, respectively. Especially the gear pump is the primary noise source when the loader is running under simulated working condition, and engine combustion next to it.

\section{Conclusions}

From the test results, we can conclude that the gear pump is the primary noise source of the wheel loader, probably caused by poor machining precision of the gears or unstable hydraulic system, and more attention should be focused on the pump in the course of noise control strategy making. 


\section{Acknowledgments}

This research was financially supported by the National Natural Science Foundation of China (Grant No. 51375268).

\section{References}

[1] N. Broner. Low frequency and infrasonic noise in transportation. Applied Acoustics, 1978, 11(2), p.129-146.

[2] R. Lotz. Railroad and rail transit noise sources. Journal of Sound and Vibration, 1977, 51(3), p.319-336.

[3] Remington, J. Paul, J. Michael, Rudd. An assessment of railroad locomotive noise, Bolt, Barenak and Newman, Inc. report prepared for Federal Railroad Administration, U.S. Department of Transportation, 1976, p.69.

[4] W. Nakkula, R. Zimmerli, R. Borough. An example of noise control treatment for construction Machinery Cab Interiors. Proceedings of the Earthmoving Industry Conference, United states, 1981.

[5] A.M. Willemsen, F. Poradek, M.D. Rao. Reduction of noise in an excavator cabin using order tracking and ultrasonic leak detection. Noise Control Engineering Journal, 2009, 57(5), p.400-412. 